\title{
O uso do modo verbal em estruturas de complementação no Português do Brasil
}

The use of verb moods in complementing structures in Brazilian Portuguese

\section{Maria do Carmo de Oliveira Mestrado/ UnB}

\section{Abstract}

The study examines the distribution of the indicative and the subjunctive in completive constructions in Brazilian Portuguese (BP), taking into consideration data from speakers of Paraíba state in Brazil. In this dialectal variety of $\mathrm{PB}$, the subjunctive was found with volitional verbs, in a nearly categorical pattern, while the indicative is preferred with verbs of opinion, although the subjunctive is also found. Accordingly, the data from Paraíba display a different pattern as compared with other dialectal varieties of BP, while they can be identified with the description of European Portuguese found in the literature.

Keywords

Complementation, Modality, Verb mood, Volitive verbs, Opinion verbs.

\section{Resumo}

O estudo examina a distribuição dos modos indicativo e subjuntivo em estruturas de complementação, no português do Brasil, considerando, de modo particular, dados de fala da Paraíba. Nessa variedade dialetal do $\mathrm{PB}$, encontramos uso quase categórico do subjuntivo com os verbos volitivos, e ampla utilização do modo indicativo com verbos de opinião, embora se verifique a flutuação com o modo subjuntivo, em alguns 
casos. Nesse sentido, os dados da Paraíba distinguem-se, por um lado, dos resultados obtidos em estudos prévios relativos a outras variedades dialetais (particularmente do RJ e de Brasília), e identificam-se, por outro, com a descrição encontrada na literatura para o português europeu.

\section{Palavras-chave}

Complementação, Modalidade, Modo verbal, Verbos volitivos, Verbos de opinião. 


\section{INTRODUÇÃO}

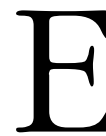

ste trabalho ${ }^{1}$ tem por objetivo examinar a distribuição dos modos indicativo e subjuntivo em estruturas de complementação, no português do Brasil (doravante, PB), considerando, de modo particular, dados de fala do estado da Paraíba. O interesse em examinar tais dados se deve ao fato de que existem evidências de que essa variedade dialetal do PB apresenta tendência de retenção do contraste entre o indicativo e subjuntivo no modo verbal, em contraste com a tendência inversa observada em estudos prévios em dados de fala das regiões Sudeste e Centro-Oeste.

O estudo será desenvolvido no quadro teórico da variação paramétrica, isto é, em uma abordagem fundamentada na teoria de Princípios e Parâmetros (CHOMSKY, 1981, 1986) em articulação com pressupostos da Teoria Variacionista (LABOV, 1972), o que implica considerar que a explicação para os fenômenos acerca da variação e da mudança lingüística pode ser atribuída a fatores determinados pela faculdade de linguagem, e também a fatores externos, que se definem por propriedades cognitivas e psicossociais, tomando-se por base a língua no contexto social.

As estruturas completivas são aquelas chamadas pela gramática tradicional (GT) de orações substantivas, dada sua distribuição nas posições sintáticas ocupadas por substantivos - como a posição de objeto direto, objeto indireto, complemento nominal e sujeito, ilustradas em (1) a (4), respectivamente. ${ }^{2}$

(1) Eu quero que Ana chegue logo.

(2) Tudo depende de que Ana chegue logo.

(3) Nós temos necessidade de que Ana chegue logo.

(4) Convém que Ana chegue logo. 
Foi constatado, em estudo de Rocha (1997), que, nas regiões CentroOeste e Sudeste do Brasil, existe variação entre as formas verbais do modo indicativo e do subjuntivo em contextos de complementação. Dos dados de Rocha (1997, p. 62), destacamos os seguintes:

(5) Aí, eu não queria que ele ficava comigo.

(6) Aí começaram a lutar, mas ele também não queria porque não queria que ela ficasse doente, né?

No francês canadense, Poplack (1992) também constata esse tipo de variação. A autora encontra dados com o modo subjuntivo na oração subordinada, em contextos nos quais, pela tradição gramatical normativa, esse modo não deveria ser utilizado. É o caso de construções com a expressão avoir l'espoir (ter esperança/ esperar), por exemplo, na oração matriz:

(7) J'espère qu'ils soient pas trop ingrats parce que je pense qu'il y en a beaucoup qui sont ingrats aujourd'hui.

Espero que eles não sejam muito ingratos, porque acho que há muitos que são hoje em dia.

(8) Mais j'espère que je serais capable de passer à travers.

Mas espero que eu seja capaz de atravessar.

Conforme mencionado, parece existirem evidências de que, no Nordeste, o subjuntivo é mais produtivo nas estruturas completivas, não ocorrendo, portanto, a situação identificada no português do Sudeste e do Centro-Oeste (ou ainda no francês canadense) de o indicativo ser usado no campo do subjuntivo. Essa observação se baseia em conhecimento intuitivo do vernáculo da região, além de correlações com resultados de pesquisas quantitativas que apontam indiretamente para a incidência maior das formas do subjuntivo nessa região. É o caso do estudo de Sampaio (2001) acerca do uso do imperativo em Salvador, que identifica alta frequiência de uso do subjuntivo na expressão do imperativo gramatical (28\% de indicativo e $72 \%$ de subjuntivo), o que contrasta com resultados obtidos por Scherre (2002) e Lima (2005), entre outros, relativos a outras regiões brasileiras, Sudeste e Centro-Oeste, em que a ocorrência do imperativo associado à forma do 
indicativo é verificada em mais de $95 \%$ das amostras de língua falada. Trabalhos em andamento com dados de Recife e de Fortaleza apontam para um equilíbrio entre as formas associadas ao indicativo e ao subjuntivo no uso do imperativo (cf. respectivamente, TEIXEIRA DE JESUS, 2005, CARDOSO - em preparação). ${ }^{3}$

O quadro que se forma, então, em relação ao uso do modo indicativo e subjuntivo em orações completivas é de variação nas regiões Centro-Oeste e Sudeste do Brasil, de acordo com os resultados obtidos em Rocha (1997) e de variação no francês canadense, com base no estudo feito por Poplack (1992). Em relação à seleção desses modos para o uso do modo imperativo, as evidências confirmam haver variação também: os dados de Salvador, analisados por Sampaio (2001) evidenciam alta freqüência do subjuntivo; nas regiões Centro-Oeste e Sudeste, Scherre (2002) e Lima (2005) encontram maior ocorrência do indicativo; em dados de Recife e de Fortaleza, Cardoso (2004) e Teixeira de Jesus (2005), verificam uso equilibrado das formas indicativa e subjuntiva no modo imperativo.

Embora reconheçamos as diferenças dialetais no Brasil e, internamente, nas regiões, é interessante notar que as variedades dialetais do Nordeste apresentam marcas que as contrastam com aquelas das regiões Centro-Oeste e Sudeste. Os resultados das pesquisas relativas à expressão gramatical do imperativo no Nordeste nos remetem, portanto, a um exame mais apurado das estruturas de complementação. É o que nos propomos desenvolver no presente estudo, limitando-nos às orações substantivas. Cabe ainda ressaltar que a alternância entre o indicativo e o subjuntivo nem sempre corresponde a uma questão de variação, havendo situações em que um mesmo predicado admite ambas as formas, de que resultam interpretações distintas, conforme será demonstrado na discussão a ser elaborada a seguir.

Para o presente estudo, coletamos dados de entrevistas com falantes da Paraíba, publicadas na obra Projeto Variação Lingüística no Estado da Paraíba - VALPB, organizada por Dermeval da Hora e Pedrosa (2001). A sistematização dos dados leva em consideração os tipos de verbo da oração principal, considerando-se, em particular, os verbos volitivos, aqueles que expressam vontade, desejo do sujeito da enunciação (DUBOIS et al., 2004, p. 615) como querer, pedir, esperar e os verbos de opinião, que expressam conhecimento, crença (MATEUS et al., 2003, p. 261) como achar, crer, acreditar. 
Os resultados da análise dos dados da Paraíba vêm confirmar a hipótese inicial desse estudo em relação à sintaxe do modo verbal em estruturas completivas: com os verbos volitivos, encontramos um uso quase categórico do subjuntivo; com os verbos de opinião, existe ampla utilização do modo indicativo, cabendo, porém, destacar ocorrência de flutuação com o modo subjuntivo, em alguns casos. No entanto, a negação, que tende a favorecer o uso do subjuntivo nos dados das regiões Sudeste e Centro-Oeste, parece não apresentar a mesma influência nos dados da Paraíba. Esses resultados nos conduzem a um estudo mais apurado do fenômeno. Com essa análise, temse por objetivo sistematizar propriedades da sintaxe do modo verbal, identificando-se a distribuição das formas do indicativo e do subjuntivo, além das propriedades sintático-semânticas a elas associadas. Espera-se ainda contribuir para a caracterização das variedades dialetais do Nordeste, o que permitirá uma comparação com os resultados encontrados em outras regiões mencionadas.

O estudo estrutura-se da seguinte forma: no item 2, investigamos o conceito de modalidade, ressaltando a necessidade de distinguir modalidade e modo verbal; no item 3 , apresentamos estudos que examinam a sintaxe dos modos indicativo e subjuntivo no português e no francês canadense, os quais adotam a perspectiva variacionista; no item 4, apresentamos os dados da Paraíba, considerando a distribuição das formas do subjuntivo e do indicativo em função dos tipos de verbos da oração matriz, bem como outros fatores correlatos à caracterização das propriedades sintático-semânticas que expressam. Por fim, apresentamos nossos resultados seguidos das considerações finais e dos questionamentos motivadores para aprofundamento do estudo.

\section{MODALIDADE E MODO VERBAL}

De acordo com Ducrot e Todorov (1977, p. 294), um ato de enunciação apresenta o mesmo conteúdo representativo, denominado dictum (relação do predicado com o sujeito) e modus (atitude que o sujeito falante toma em relação ao conteúdo). Adotando esse tipo de distinção, Botelho Pereira (1974, p. 66-70) discute as sentenças de (9) a (16), ressaltando que apresentam o mesmo dictum, embora remetam a um modus (ou modalidade) diferente. 
(9) Pedro viajou.

(10) Pedro viajou?

(11) Pedro viajou!

(12) Pedro viajou?!

(13) Pedro não viajou.

(14) a. Pedro viajou, talvez.

b. Pedro deve ter viajado.

c. Pedro terá viajado.

d. Parece que Pedro viajou.

e. Acho que Pedro viajou.

f. Paulo disse que Pedro viajou.

(15) a. Pedro viajou!

b. Lamento que Pedro viajou.

c. Alegra-me que Pedro tenha viajado.

d. Admira-me que Pedro tenha viajado.

(16) a. Oxalá Pedro viaje!

b. Quero que Pedro viaje!

c. Não quero que Pedro viaje.

De acordo com a autora, o estado de coisas descrito em (9) constitui um fato único, que pode ser apresentado de diferentes formas, dependendo de como será distribuída a informação, o que é feito pela articulação entre o tópico, que é a informação conhecida, e o comentário, que é a informação nova. O fato é que em (9) tanto Pedro, o sujeito sintático, quanto viajou, o predicado sintático, podem assumir o papel de tópico ou comentário. Se o enunciado responde à pergunta "Quem viajou?", Pedro é comentário e viajou é tópico. Se responde à pergunta "O que fez Pedro?", Pedro passa a ser tópico e viajou, comentário. Pode ainda acontecer de todo o enunciado "Pedro viajou" corresponder à informação nova, caso responda à pergunta: "O que aconteceu?" 
As construções de (10) a (16) apresentam o dictum de (9) modificado, ou seja, com o modus diferente. A descrição do estado de coisas pela qual é estabelecida a relação entre 'Pedro' e 'viajou', aparece em (10), (11) e (12) com a marca de um elemento psicológico, que é a natureza subjetiva da ligação que o locutor estabelece entre o sujeito e o predicado. Nesses três casos, a diferença de sentido se manifesta por uma marca prosódica: a interrogação, a exclamação e a associação das duas. Em (13), a negação constata que não há ligação entre o sujeito e o predicado na realidade objetiva.

Pereira (1974) observa que, na língua, duas idéias distintas podem ser colocadas em diferentes tipos de correlações: em um extremo a existência de uma ligação positiva, que se constata objetivamente (oração declarativa afirmativa) ou acrescida de marcas emocionais ou avaliativas do locutor (oração exclamativa) e, no outro extremo, a ausência dessa ligação (oração negativa). E acrescenta que, no meio desses extremos, existe uma ligação entre as idéias que é questionada, colocada em dúvida (oração interrogativa).

Para a autora, essas correlações podem ter caráter objetivo, como nos casos analisados de (9) a (13), ou caráter subjetivo, nas seguintes situações: (i) quando "expressam a ligação do sujeito com o predicado como um fato existente apenas no pensamento do locutor, ou como um relato sobre cujo conteúdo o locutor não se responsabiliza pessoalmente" (p. 69-70), o que se constata em (14); (ii) "quando manifestam o envolvimento emocional ou avaliativo do locutor em relação à ligação afetiva que constata entre sujeito e predicado" (p. 70), o que se verifica em (15); (iii) "quando manifestam sentimento de vontade do locutor de que a ligação entre sujeito e predicado venha ou não venha a se realizar" (p. 70), como em (16).

Tais aspectos permitem concluir que os exemplos de (9) a (16) ilustram a manifestação de marcas que caracterizam a modalidade, as quais podem ser sistematizadas como a seguir: (i) o grau de realização de ligação entre o sujeito e o predicado (a verdade, a possibilidade, a dúvida, a negação); (ii) o grau de responsabilidade do locutor em relação à afirmação ou negação dessa ligação; (iii) a natureza da ligação (relação de causa e efeito ou de necessidade) ou das condições satisfeitas para que a ligação se tenha realizado ou se realize; (iv) a natureza do envolvimento subjetivo (emocional ou avaliativo) do locutor em relação a essa ligação.

A autora acrescenta que a subjetividade é um componente da definição de modalidade, que pode ou não se associar a alguma noção modal, a qual, por 
sua vez, não é necessariamente subjetiva. A ligação entre o sujeito e o predicado pode ser tida como necessária ou possível, o que, muitas vezes, pode ser de natureza psicológica, ou seja, motivada internamente pelo locutor, como em (17), ou decorrente da natureza dos fatos correlacionados, como em (18).

(17) Eu necessito que você me perdoe.

(18) É necessário que todo efeito tenha uma causa.

Ainda em relação à codificação lingüística da modalidade, Pereira (1974) destaca o fato de que enunciados formulados em oração simples (declarativa, interrogativa), que recebem uma qualificação modal por meio de marca prosódica (asserção, interrogação, exclamação), de modificadores lexicais (talvez, oxalá, impreterivelmente, possivelmente), de verbos modais (dever, poder), podem expressar a idéia de significação interrogativa, exclamativa, dubitativa, optativa, imperativa pela subordinação sintática, conforme ilustrado a seguir:

(19) a. Pedro viajou?

a'. Pergunto se Pedro viajou.

b. Pedro viajou!

b'. Surpreende-me que Pedro tenha viajado.

c. Pedro viajou, talvez. Pedro deve ter viajado.

c'. Acho que Pedro viajou.

d. Oxalá Pedro viaje.

d'. Desejo que Pedro viaje.

e. Pedro viajará impreterivelmente. Pedro viajará.

e'. Ordeno que Pedro viaje.

É interessante notar que a utilização da estrutura subordinada na codificação da modalidade tem como corolário a manifestação da oposição entre o modo indicativo e o modo subjuntivo. De fato, verifica-se que o modo indicativo ocorre com os predicados 'perguntar'(19a') e 'achar' (19c'), enquanto o subjuntivo ocorre com os predicados 'surpreender' (19b'), 'desejar' (19d') e 'ordenar' (19e'). Recorremos então ao questionamento feito 
por Pereira (1974), o qual se mostra pertinente ao presente estudo: "qual o papel da variação morfológica do verbo nos paradigmas de indicativo e de subjuntivo na expressão da modalidade?" (p.75).

Conforme amplamente observado na literatura gramatical, os verbos possuem recursos morfológicos próprios para expressar a modalidade por meio dos paradigmas de indicativo e subjuntivo, que apresentam formas capazes de, ao menos em estruturas superficiais, oporem-se semanticamente entre si. Existe consenso entre os gramáticos em relação às definições do modo indicativo e do modo subjuntivo. Cunha \& Cintra (1985) orientam que o uso do verbo no modo indicativo é para expressar um fato tido como certo, real, no presente, no passado ou no futuro. O verbo no subjuntivo, por sua vez, denota o fato como uma coisa incerta, duvidosa, eventual ou mesmo irreal. Os gramáticos contrapõem, portanto, o uso do modo subjuntivo ao indicativo, ressaltando o contraste na atitude de falante quando é utilizado esse ou aquele modo.

Mattoso Câmara (1981) afirma que o indicativo é o modo verbal mais geral e básico da língua portuguesa; é o modo que assegura um fato; e o subjuntivo é o modo verbal com a tarefa de mostrar que o processo é apenas admitido em nosso espírito, sendo, então, passível de dúvida, opondo-se ao indicativo. No entanto, segundo o autor, o indicativo assume a área dos dois, ficando para os advérbios o papel de marcadores da modalidade de dúvida e da vontade. O subjuntivo, continua Mattoso, representa no português de hoje uma servidão gramatical (grifo nosso), só sendo usado em tipos especiais de frases.

Pereira (1974), respondendo à pergunta feita anteriormente, afirma que a possibilidade de duas orações serem diferenciadas semanticamente pelo modo verbal, mantendo-se os outros aspectos idênticos, fornece as bases para que gramáticos e lingüistas definam o indicativo e o subjuntivo, conforme se percebe nas definições de Cunha \& Cintra (1985) e Mattoso Câmara (1981), mencionadas anteriormente. A autora, entretanto, avança nessa discussão e propõe uma caracterização da oposição entre o modo subjuntivo e o modo indicativo, por meio de três funções: ${ }^{4}$

(i) função semântica: quando há oposição em contextos sintáticos pelo menos superficialmente idênticos, a oração principal não condiciona o modo da subordinada, o que quer dizer que pode haver alternância. $\mathrm{O}$ locutor pode escolher um ou outro modo, conforme o que queira expressar, visto que o uso de um ou outro acarreta significados diferentes. 
(20) Pedro caiu de modo que quebrou a perna.

(21) Pedro caiu de modo que quebrasse a perna.

Em relação à função semântica que representa a oposição entre o subjuntivo e o indicativo, os exemplos ilustram com clareza o contraste de interpretação. Em (20), o locutor refere-se a um fato real: existe um sujeito 'Pedro' do evento 'cair', seguido da conseqüência real do evento, 'quebrou a perna'. Em (21), o locutor refere-se a um sujeito (real) 'Pedro' do evento 'cair', e a uma conseqüência do evento descrita como uma possibilidade: o evento poderia, mas não necessariamente deveria, resultar na perna quebrada (grifo nosso).

(ii) função gramatical: reservada ao subjuntivo, que aparece como marca de subordinação; o modo é condicionado pela oração principal, significando que o valor de verdade da oração subordinada não determina o modo verbal.

(22) Desejo que Pedro se recupere./ *Desejo que Pedro se recupera.

(23) Esperei que ele viesse./ *Esperei que ele vinha.

Em relação à função gramatical, a autora afirma que a modalidade já está marcada na oração principal, sendo, portanto, redundante a semântica do modo verbal na subordinada, o que torna essa categoria um marcador gramatical da subordinação. É o caso, por exemplo, de construções com verbos volitivos na oração matriz, em que se depreende uma interpretação que remete a um 'desejo', a uma 'vontade', mantendo-se, portanto, no plano da possibilidade.

Essa definição se aplica de forma clara a uma gramática que tenha categoricidade no uso do modo subjuntivo nesses contextos. Conforme mencionado anteriormente, estudos mostram que, em algumas variedades dialetais do $\mathrm{PB}$, existe o uso variável do modo subjuntivo e indicativo exatamente nesse contexto, o que impede o tratamento do modo subjuntivo como marcador gramatical da subordinação, nos termos de Pereira, pelo menos em relação a essas variedades. É interessante observar que, ainda assim, a classificação da autora se mantém no que se refere ao fato de a modalidade estar codificada na oração matriz, o que, provavelmente, explica o uso variável do modo verbal na subordinada. 
(iii) função semântico-gramatical: quando as modalidades expressas pela oração matriz e pela oração encaixada são compatíveis e a primeira condiciona o modo da segunda, isto é, o modo verbal da encaixada é determinado pela oração matriz.

(24) Sei que chove./*Sei que chova.

A função que Pereira (1974) chama de semântico-gramatical diz respeito à compatibilidade entre a expressão da modalidade da oração matriz e da oração subordinada. Em (24), o verbo saber indica a certeza do locutor em relação ao conhecimento de algo. Por sua vez, o evento denotado como objeto do conhecimento do locutor é interpretado como real, e não como uma possibilidade. Por essa razão, em (24), o modo da subordinada é o indicativo, que codifica a interpretação da certeza compatível com a semântica do verbo saber, na matriz; o modo subjuntivo é excluído desse contexto, exatamente pelo fato de remeter à interpretação da incerteza, da possibilidade, que não é compatível, nesse caso, com o grau de certeza do verbo da matriz (e essa restrição é observada mesmo em uma gramática em que ocorre a variação entre o indicativo e o subjuntivo, como no caso das construções com verbos volitivos). Como o indicativo é única forma possível, além do valor semântico, sua ocorrência adquire um valor gramatical.

A classificação proposta por Pereira (1974) será adotada na discussão dos resultados obtidos no presente estudo em relação aos dados da Paraíba, bem como daqueles encontrados em estudos prévios relativos a outras variedades dialetais do PB e de outras línguas. Como será demonstrado, nossos resultados apontam para a necessidade de ampliar as considerações a respeito da distribuição do modo verbal.

\section{ESTUDOS PRÉVIOS DE VARIAÇÃO NO MODO VERBAL EM DIALETOS DO PB E NO FRANCÊS CANADENSE}

\subsection{O estudo de Rocha (1997) sobre o PB com dados do Rio de Janeiro e de Brasília}

Nesta seção, apresentamos o estudo feito por Rocha (1997) acerca da distribuição do modo verbal em dados de fala do Rio de Janeiro e de Brasília, 
no qual são identificados casos de variação entre o subjuntivo e o indicativo, sendo a discussão desses casos desenvolvida no âmbito do variacionismo laboviano.

A autora tem por hipótese inicial a perda de campo do modo subjuntivo para o modo indicativo em diversos ambientes sintáticos. Como evidência forte, Rocha (1997) parte de conclusões de diversos trabalhos sobre o imperativo no $\mathrm{PB}$, cujos resultados apontam para a perda significativa da forma do imperativo associada ao subjuntivo, o que indica um afastamento em relação ao que é apresentado pela norma gramatical.

O estudo de Rocha (1997) restringe-se às orações subordinadas substantivas, limitando-se ainda a estudar a alternância das formas verbais que estejam no presente e no pretérito imperfeito. A autora considera relevante para o seu estudo o seguinte grupo de fatores: (i) carga semântica do verbo ou do sintagma verbal da matriz; (ii) faixa etária do falante; (iii) estrutura da assertividade da oração matriz; (iv) regularidade verbal e tipo de verbo da oração encaixada; (v) tempo do verbo da oração matriz e tempo do verbo da oração encaixada.

Na análise dos dados, Rocha (1997) identifica nove classes semânticas de verbos, baseando-se na categorização feita por Pereira (1974). Para este estudo, interessa-nos mostrar apenas os resultados obtidos em dois grupos: os verbos volitivos, que estão situados no grupo dos factivos, ${ }^{5}$ e os verbos de opinião, ${ }^{6}$ que estão situados no grupo dos verbos e predicados indiferentes. ${ }^{7}$

Para Pereira (1974) cada categoria semântica tem, de acordo com o valor de verdade que se queira atribuir ao enunciado, um modo verbal predeterminado. De acordo com a divisão que a autora faz dos verbos, os volitivos selecionam categoricamente o subjuntivo. Quanto aos verbos de opinião, admite-se a alternância, não a variação (cf. seção 2).

Os resultados obtidos por Rocha (1997) divergem das previsões de Pereira: com os volitivos, ainda que sejam grandes favorecedores do subjuntivo (apresentam um peso relativo de 0,95 ), ocorrem formas verbais também do indicativo. Rocha observa que essa variação entre o subjuntivo e o indicativo, conforme se verifica no dado em (25), em oposição a (26), (27) e (28), é difundida entre os diferentes os grupos de falantes, e não muito estigmatizada, principalmente se o tempo verbal da encaixada é o presente.

(25) Eu quero que você verifique o óleo e o nível da água da bateria da próxima vez. 
(26) Você quer qu'eu ligo pra você quando eu chegar?

(27) Espero que algum dia o governo federal olha de uma maneira mais positiva pr'aqui ...

(28) Se a gente for lá falar: a prufessora tá pidino ${ }^{8}$ que coloca água den' do filtro...

Em relação aos verbos de opinião, que fazem parte de um grupo dos verbos indiferentes, caracterizados como aqueles que não atribuem à oração subordinada um valor de verdade que possa ser inferido das propriedades do predicado, o estudo de Rocha (1997) aponta para uma alternância entre as formas verbais: ambientes onde se espera o subjuntivo vão sendo ocupados pelo indicativo e ambientes onde se prevê o indicativo vão sendo ocupados pelo subjuntivo, como ocorre com o verbo achar. De acordo com a autora, esse verbo é desfavorecedor do modo subjuntivo, mas, quando negado na matriz, favorece a forma subjuntiva (da mesma forma como propõe Pereira, 1974). Os exemplos (29) e (30) mostram o comportamento do verbo achar.

(29) Eu achei que seu nome fosse fulano... /...ela acha que eu devo dar um tapinha...

(30) Eu não a acho que seja mais fácil, não./ Eu não sei, mas você não acha que ela é a mãe do Luís Carlos?

É importante mostrar também o resultado obtido por Rocha (1997) em relação à influência de três fatores sociais: faixa etária, escolaridade e sexo do falante. Desses três, o mais relevante estatisticamente é a faixa etária, cuja análise se dá como se cada faixa representasse uma época diferente. A autora destaca, para análise dessa variável, dois padrões que se distinguem: linear, no qual o falante mais jovem utiliza a forma inovadora, ao passo que o falante mais velho mostra preferência pela forma mais conservadora; outro padrão é o curvilinear, no qual falante jovem e falante velho têm o mesmo comportamento, o que caracteriza a variação estável.

Os resultados de Rocha (1997) indicam um padrão linear: falantes com mais de 50 anos de idade usam mais o subjuntivo tanto em ambientes em que o subjuntivo é preferencial quanto em ambientes preferenciais de uso do indicativo $(0,82)$, ao passo que os falantes mais jovens usam menos o 
subjuntivo nos dois ambientes $(0,26)$. Os níveis intermediários, de 15 a 25 anos e de 26 a 44 anos, aparecem com uma possibilidade de $(0,48)$ a $(0,58)$, respectivamente, de peso relativo.

Apresentamos os fatores sociais escolaridade e sexo, embora não considerados estatisticamente significativos pelo programa para o fenômeno da alternância no estudo de Rocha (1997). De acordo com os resultados, não há grandes diferenças entre os valores dos pesos relativos dos diferentes níveis de escolaridade: $2^{\circ}$ grau, 0,$55 ; 1^{\circ}$ grau completo, 0,$44 ;$ e $1^{\mathrm{a}}$ a $4^{\mathrm{a}}$ série do $1^{\mathrm{o}}$ grau, 0,51. A variável sexo mostra um desfavorecimento do uso da forma subjuntiva pelas mulheres: com peso relativo de 0,47 , em oposição a 0,54 , referente ao resultado de uso do subjuntivo pelos homens.

Segundo vários estudos, as mulheres tendem a se mostrar mais sensíveis em relação às formas lingüísticas de prestígio, mas também são as mulheres que demonstram mais sensibilidade à variação, desde que a variante inovadora não seja estigmatizada pela sociedade (cf. LABOV, 1990; OLIVEIRAE SILVA \& PAIVA, 1996).

Em suas considerações finais, após a análise de fatores lingüísticos e extralingüísticos, Rocha afirma que não é exclusividade da semântica do verbo da matriz a determinação do modo verbal da oração encaixada. Como as gramáticas tradicionais e alguns estudos apresentam, outros fatores como faixa etária do falante, estrutura da assertividade da oração matriz, regularidade verbal e tipo de verbo da oração encaixada e tempo do verbo da oração matriz e tempo do verbo da oração encaixada, bem como devem ser considerados. Para a autora, o modo indicativo e o modo subjuntivo estão em alternância, tomando-se como base os dados do Rio de Janeiro e de Brasília.

\section{2 $O$ estudo de Poplack (1992) sobre o francês canadense}

O francês canadense, que, como o português do Brasil, pertence ao grupo das línguas românicas, foi estudado, em relação ao uso do modo verbal em orações completivas, por Poplack (1992), também em uma perspectiva variacionista. A autora questiona a posição tradicional da gramática francesa, segundo a qual a escolha do modo na oração encaixada é inteiramente automática, conseqüência da natureza do verbo da matriz, o que torna o modo verbal uma marca redundante de subordinação. Poplack (1992) parte do pressuposto de que a alternância entre subjuntivo e indicativo não expressa uma 
diferença de significado, o que poderia ser definido como o comprometimento do locutor com a realidade, com a probabilidade ou o valor de verdade da proposição complementar. Para essa autora, são formas variantes, conforme ilustrado em (31) e (32).

(31) Mais quande tu es jeune, moi je crois que c'est une-une bonne chose.

Mas quando você é jovem, eu acho que isso é uma coisa boa.

(32) Je crois pas que ce soit la fin du monde.

Não acho que seja o fim do mundo.

A gramática francesa, segundo Poplack (1992), apresenta três classes de matrizes verbais, definidas de acordo com os critérios a seguir: (1) requer subjuntivo sempre; (2) nunca requer o subjuntivo e (3) admite a ocorrência do modo subjuntivo. Poplack (1992) afirma, no entanto, que, com essa divisão, não se consegue sistematizar com precisão o uso do modo subjuntivo. Na tabela 1, pode-se verificar essa distribuição.

TABELA 1

Distribuição de subjuntivos encaixados de acordo com a matriz verbal

\begin{tabular}{lll}
\hline $\begin{array}{c}\text { Subjuntivo categórico } \\
(100 \%)\end{array}$ & Subjuntivo variável & Nenhum subjuntivo \\
\hline Dire /dizer & Vouloir/querer (91\%) & Prier /rezar \\
Demander /pedir & Avoirpeur / ter medo (64\%) & Se plaindre / queixar-se \\
Concevoir/conceber & Penser / pensar (13\%) & Etre surpris / estar surpreso \\
Désirer / desejar & Empêcher / impedir (8\%) & Avoir l'espoir / esperar \\
\hline
\end{tabular}

Assumindo que o uso do subjuntivo no francês canadense é variável, a autora não descarta a possível correlação semântica entre o verbo da matriz e o uso do modo. No entanto, analisa outros fatores, como: (i) o grau de asserção do complemento encaixado; (ii) a presença de indicadores lexicais de expressão de modalidade; (iii) o tempo verbal; (iv) a concordância de tempo verbal dos verbos da oração matriz e da encaixada; (v) a presença explícita ou não de complementizador que; (vi) a presença ou não de material interveniente entre os verbos das orações e a estrutura morfológica do verbo encaixada.

Poplack (1992) menciona ainda que, segundo a norma gramatical, os verbos emotivos e os volitivos necessitam do subjuntivo em todos os 
contextos (subjuntivos primários), e os verbos de opinião só o exigem quando são negados (subjuntivo secundário). Esses verbos, que estão presentes em quase todas as matrizes analisadas por Poplack (1992), ficam assim distribuídos, segundo sua análise: os verbos volitivos permanecem como maiores favorecedores do modo subjuntivo $(0,77)$; os emotivos que, ao longo do desenvolvimento da língua, estiveram entre o indicativo e o subjuntivo, embora continuem favorecendo o uso do subjuntivo, tiveram uma redução de intensidade de uso $(0,66)$; os verbos de opinião negados, que acrescentam agora a condição de que só necessitam do subjuntivo quando a matriz é negativa $(0,9)$.

Segundo Poplack (1992), mesmo em face dos resultados obtidos, não se pode afirmar que o subjuntivo perdeu seu sentido nas orações substantivas no francês canadense. Acredita, porém, que a variação entre o indicativo e o subjuntivo tem-se mantido historicamente, embora gramáticos, professores, lingüistas, e até os dados, conspirem para apresentar os resultados de forma diferente - isto é, para que a variação seja ignorada. De fato, levando-se em conta a trajetória do subjuntivo do latim clássico ao francês arcaico, não se pode considerar inesperados os fatos descritos, analisa Poplack (1992), bem como não se pode mostrar movimento dos verbos de uma classe para outra sem que tenha havido um período anterior de variabilidade.

As observações de Poplack (1992) quanto à trajetória do subjuntivo na diacronia podem ser estendidas ao português, notadamente ao tratamento que tal fenômeno recebe dos gramáticos e dos filólogos. No entanto, mesmo sabendose do interesse desses autores em buscar estabelecer uma norma, é possível identificar, no texto gramatical de alguns deles, referências ao uso variável do indicativo e do subjuntivo. Em Said Ali (1964, p. 170), por exemplo, ressalta-se que a variação entre o indicativo e o subjuntivo é observada desde o português arcaico: "A linguagem atual flexiona o verbo das concessivas no modo subjuntivo; no tempo de Vieira, entretanto, século XVI, a flexão alternava-se entre os modos indicativo e subjuntivo." Bechara (1999), por sua vez, afirma que não há rigor a respeito do uso do modo subjuntivo nas concessivas, sendo essa variação também verificada nas orações em que se utiliza o advérbio talvez, ambiente onde, por indicar fatos incertos e duvidosos, seria esperado o modo subjuntivo.

Além da gramática tradicional, estudos no âmbito da lingüística, não necessariamente orientados pelo enfoque variacionista, vêm confirmar essas observações. Pereira (1974), citada anteriormente, faz referência à alternância entre o subjuntivo e o indicativo como um fenômeno condicionado pelo grau 
de formalidade do discurso - uma questão que a autora não aprofunda, embora mereça elaboração, conforme observado por Farias (2005). Examinando aspectos sintáticos e semânticos de construções introduzidas pelas conjunções 'embora' e 'mas' em textos escritos por estudantes da Educação Básica (ensino médio e fundamental ( $2^{\circ}$ ciclo)), o trabalho de Farias (2005) também identifica variação no uso do modo verbal em orações concessivas, ${ }^{9}$ conforme (33) e (34):

(33) Embora Maria estudou muito, a sua nota foi péssima.

(34) As provas estão chegando, embora eu estou estudando, tenho medo de tirar notas ruins.

Passamos a seguir ao exame dos dados da Paraíba, a fim de retomar a discussão acerca do uso variável do subjuntivo e do indicativo no PB, o que permitirá estabelecer comparação com os resultados de Rocha (1997) e Poplack (1992).

\section{O MODO VERBAL EM ESTRUTURAS DE COMPLEMENTAÇÃO NOS DADOS DA PARAÍBA}

\subsection{Caracterização do corpus - o VALPB - Projeto Variação Lingüística no Estado da Paraíba}

Como mencionamos na introdução deste trabalho, os dados do presente estudo foram retirados de entrevistas organizadas e publicadas em Dermeval da Hora \& Pedrosa (2001) no Projeto Variação Lingüística no Estado da Paraíba (VALPB). Essa amostra é bastante representativa, uma vez que controla variáveis sociolinguiísticas importantes para uma visão ampla da fala da comunidade da Paraíba, a saber: a escolarização dos falantes, a faixa etária, o gênero. O VALPB é constituído de cinco volumes, sendo as entrevistas distribuídas por tempo de escolarização, conforme indicado a seguir: Volume I - sem escolarização; Volume II - 1 a 4 anos; Volume III - 5 a 8 anos; Volume IV - 9 a 11 anos; Volume V - mais de 11 anos.

A organização da amostra da fala da Paraíba disponível na publicação em termos de variáveis sociolingüísticas é de fundamental importância para nosso estudo, em particular o controle da variável escolarização, que, 
juntamente com a variável etária e a de gênero, permite discutir de maneira mais segura algumas questões que buscamos responder. De fato, existe entendimento, especialmente nos meios escolares, de que o uso do subjuntivo, ou o seu desaparecimento do vernáculo, esteja associado ao processo de escolarização seja no sentido de pressupor que tal categoria deve ser ensinada na escola, sendo, portanto, sua ocorrência um indicador social de acesso à educação formal, seja, inversamente, no sentido de atribuir sua ausência no vernáculo à falta de acesso a determinados níveis de escolarização ou a lacunas/ falhas no processo de ensino-aprendizagem. Nesse sentido, a possibilidade de examinar os dados com base na escolarização dos falantes oferecerá elementos para investigação dessa questão.

\subsection{Os resultados relativos ao corpus da Paraíba}

\subsubsection{Construções com verbos volitivos}

Em relação aos verbos volitivos querer, pedir, ${ }^{10}$ esperar, verificamos, nos dados da Paraíba, o uso (quase) categórico do modo subjuntivo, conforme ilustrado em (35)-(37), com o verbo querer; em (38)-(39), com o verbo pedir; e em (40)-(41), com o verbo esperar.

(35) A gente vai, vai pra lá. Ela quer que eu vá de qualquer maneira.

(36) É eu queria tanto que se acabasse essa violência...

(37) Ai, Jesus! Eu quero que você me dê isso.

(38) Sempre eu peço a Deus :: saúde. Deus me dê muita paciência pra num fazer ... que Deus cubra ele, tenha compaixão.

(39) (...) eu peço a Deus isso que ele me guie, me ajude e me guarde de, de, de coisas ...

(40) (...) mais eu tô esperando que ele complete a obra.

(41) Foi muito bom e espero que todo mundo possa tirar proveito das Instituições. 
A decisão de considerar que o uso do subjuntivo é quase categórico com os verbos volitivos se deve à ocorrência do dado ilustrado em (42), a seguir:

(42) (...) espero que se Deus quiser para o ano eu continuo a istudar, se Deus quiser.

Trata-se da única manifestação do indicativo na oração completiva com verbo volitivo na matriz. Uma forma de discutir esse dado, em face dos demais, é considerar a possibilidade de que a presença de material lingüístico interveniente - a expressão se Deus quiser - tenha criado um tipo de ruptura na estrutura sintático-semântica, favorecendo a ocorrência do indicativo nessa construção. ${ }^{11}$

Apresentamos, a seguir, a tabela 2, com dados quantitativos relativos à frequiência dos predicados analisados, com o total de ocorrências no indicativo e no subjuntivo.

TABELA 2

Verbos volitivos/ anos de escolarização

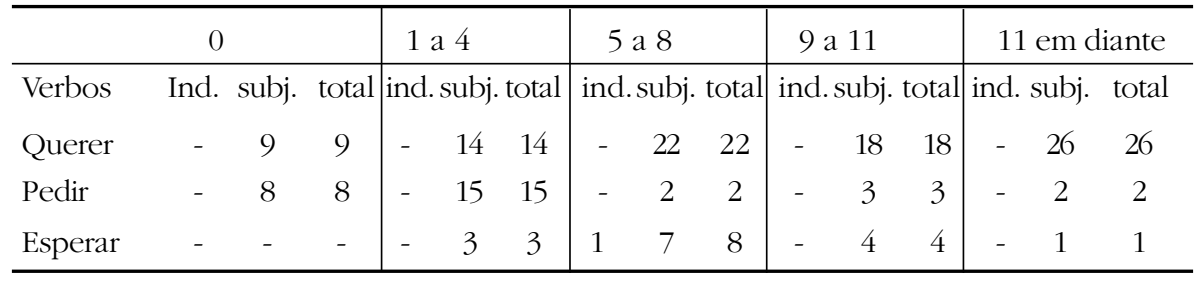

Dos 135 dados com verbos volitivos, obtivemos a seguinte distribuição: 89 ocorrências do verbo querer; 30 do verbo pedir; e 16 do verbo esperar. Excetuando-se um dado em que a oração completiva manifestou o verbo no indicativo (42), são 134 dados com verbo volitivo na oração matriz e modo subjuntivo na oração subordinada.

O uso quase categórico do subjuntivo nos dados da Paraíba distingue, portanto, essa variedade dos resultados encontrados em Rocha (1997) e em Poplack (1992). O padrão encontrado nos dados da Paraíba alinha-se, porém, não só com as considerações de Pereira (cf. seção 2) (em que se supõe que a variedade do português do Brasil utilizada como referência esteja crucialmente associada a falantes escolarizados ou a usos formais), mas também com o que é atestado em Mateus et al. (2003), em relação ao português europeu (PE). De acordo com essas autoras, no PE, verbos volitivos selecionam 
categoricamente o subjuntivo na oração subordinada, uma situação também atestada para o espanhol, conforme se verifica em diferentes gramáticas descritivas. Além disso, a tabela 2 permite constatar que a escolarização não interfere na escolha do modo verbal na oração subordinada.

\subsubsection{Construções com verbos de opinião}

Entre os verbos de opinião, foram considerados particularmente os verbos crer, achar e acreditar. Identificamos, nos dados da Paraíba, alternância entre as formas do indicativo e do subjuntivo. A seguir, apresentamos dados com cada verbo citado, agrupados pelo modo verbal da oração subordinada: Achar/ subjuntivo

(43) Eu acho que seja ótimo. Da minha parte, cum meus vizinho são ótimo.

(44) Eu num acho que seja certo isso.

(45) (...) aí acho que talvez eu num conclua o primário esse ano...

(46) Eu não acho que contribua para a violência não, apesar de muitas pessoa0 achare 0 que contribui.

Achar/indicativo

(47) Demais, eu acho que, só Deus tem, e só Deus perdoa, né?

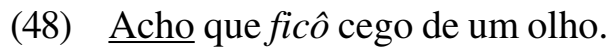

(49) Acho que ninguém tá preparado pra morrer.

(50) Eu acho que vivia melhor.

Acreditar/ subjuntivo

(51) Até hoje, eu acredito que seja a dor:: pior que existe:: é a dor de ter um filho.

(52) E daí, eu acredito que todas residências nesse bairro e proprietários estejam com os seus IPTUs em dia com a prefeitura ...

(53) Eu num acredito que exista isso (risos) paixão. 
(54) Mais eu acredito que eles precisasse ei [aju] tentaria ajudar o máximo possível...

Acreditar/indicativo

(55) Eu? Eu acredito que :: antigamente era::, quer dizer, era mais puxado do que hoje.

(56) Eu acredito que a estorinha que eu mais gostei foi a Branca de Neve...

(57) Eu acredito que depois da morte tem o nosso encontro com Deus.

Crer/subjuntivo

(58) Porque eu creio que numa cidade tão grande como essa ainda tenha gente que fique parada...

\section{Crer/indicativo}

(59) (...) mais eu creio que no fim da novela eles termina tudo bem eles dois.

(60) Eu creio que o amor ele é uma coisa progressiva.

(61) E eu creio que vou obter um dia se for fiel a ele até o fim...

(62) (...) muitas coisa que creio que não agradam só aos homens...

Apresentamos a seguir a tabela 3, com a frequiência dos verbos de opinião, considerada ainda em função da escolarização dos falantes.

\section{TABELA 3}

Verbos de opinião/ anos de escolarização

\begin{tabular}{|c|c|c|c|c|c|c|c|c|c|c|c|c|c|c|c|}
\hline \multicolumn{4}{|c|}{0} & \multicolumn{3}{|c|}{1 a 4} & \multicolumn{3}{|c|}{5 a 8} & \multicolumn{3}{|c|}{9 a 11} & \multicolumn{3}{|c|}{11 em diante } \\
\hline Verbos & Ind. & subj. & total & ind. & ubj & total & ind & ub & total & ind. & ubj & total & ind. & ubj. & total \\
\hline Achar & 19 & - & 19 & 50 & 1 & 51 & 55 & 3 & 58 & 149 & 5 & 154 & 195 & 1 & 196 \\
\hline Crer & 1 & - & 1 & 16 & 1 & 17 & - & - & - & 5 & - & 5 & 11 & - & 11 \\
\hline Acreditar & - & - & - & 6 & 3 & 9 & 2 & 1 & 3 & 1 & 1 & 2 & 10 & 1 & 11 \\
\hline
\end{tabular}

Foram encontrados 537 dados com verbos de opinião, assim distribuídos de acordo com o tipo de verbo: 478 dados com o verbo achar, dos quais 
468 verbos com o indicativo e 10 com subjuntivo na oração subordinada; 34 dados com o verbo crer dos quais 33 no indicativo e 1 com subjuntivo na oração subordinada; 25 dados com o verbo acreditar dos quais 19 com o indicativo e 6 com subjuntivo na oração subordinada. Tomando-se em separado a freqüência dos modos subjuntivo e indicativo, obtivemos 520 dados no indicativo e 17 no subjuntivo. Percebe-se, portanto, que, com verbos de opinião, tanto o modo subjuntivo quanto o modo indicativo são encontrados na oração subordinada, embora seja significativa a preferência pelo indicativo.

A distribuição geral dos verbos de opinião entre os modos indicativo e subjuntivo está representada na tabela 4.

TABELA 4

Distribuição dos verbos de opinião

\begin{tabular}{lccl}
\hline Verbos & subjuntivo & indicativo & total \\
\hline Achar & 10 & 468 & 478 \\
Crer & 1 & 33 & 34 \\
Acreditar & 6 & 19 & 25 \\
Total & 17 & 520 & 537 \\
\hline
\end{tabular}

Esses resultados apontam para uma semelhança em relação àqueles obtidos nos estudos de Rocha (1997) e de Poplack (1992), com o mesmo grupo de verbos. Mateus et al. (2003) também fazem referência ao uso variável do modo verbal no PE, com esse tipo de verbo, assim como Pereira (1974).

Ao considerarmos separadamente cada verbo, verificamos, porém, que os dados da Paraíba não correspondem de forma exata ao padrão descrito por Mateus et al. (2003) para o PE, pois, segundo as autoras, no PE, os verbos crer e achar ocorrem apenas com o indicativo, ao passo que acreditar ocorre tanto com o indicativo quanto com o subjuntivo. Essa divergência se dá basicamente com o verbo achar, que, nos dados da Paraíba, e diferentemente do PE, apresenta uso variável do modo verbal na oração subordinada, ainda que o indicativo tenha alta freqüência; o verbo crer só apresenta uma ocorrência do subjuntivo, o que nos leva a afirmar que seu uso com o indicativo é quase categórico nos dados da Paraíba; o verbo acreditar, por sua vez, tem comportamento semelhante ao encontrado no PE, verificando-se a alternância entre o modo indicativo e o subjuntivo. 
Nos dados do Rio de Janeiro e de Brasília, Rocha (1997) constata que o verbo achar, analisado em conjunto com os outros verbos do grupo, desfavorece o uso do subjuntivo na oração encaixada, o que leva à redução significativa no percentual de incidência do modo subjuntivo nos dados. Excluindo o verbo achar do grupo, Rocha constata que, com os demais verbos, há favorecimento do modo subjuntivo, diferentemente do que encontra Poplack (1992), no francês canadense, em que os verbos de opinião são menos favorecedores do subjuntivo.

Para Pereira (1974), o verbo achar apresenta baixo grau de formalidade, o que justifica o uso mais freqüente do modo indicativo na oração subordinada, por ser este o modo menos marcado e menos formal.

Constata-se ainda que, com verbos de opinião, o subjuntivo é encontrado nas diferentes faixas de escolarização, exceto naquela em que os falantes não têm escolaridade alguma, o que sugere ainda assim, que, como no caso dos verbos volitivos, o grau de escolarização não é significativo em relação ao uso do modo verbal na oração subordinada (embora seja importante aprofundar essa questão, em face dos resultados referentes aos falantes não escolarizados).

Na próxima seção, passamos a examinar a interferência da negação na seleção do modo verbal da oração encaixada com os verbos de opinião na oração matriz, considerando os resultados obtidos nos dados da Paraíba em confronto com os resultados encontrados nos demais estudos.

\subsection{3 $O$ papel da negação na distribuição do modo verbal com verbos de opinião}

Em relação aos dados da Paraíba, constata-se o seguinte: com os verbos achar e acreditar, o subjuntivo é encontrado com ou sem elemento de negação. A presença da negação na oração matriz, no entanto, é favorecedora do modo subjuntivo, o que sugere o mesmo condicionamento observado nos estudos de Rocha (1997) e Poplack (1992) e na descrição de Mateus (2003) para o PE.

(63) (...) aí acho que talvez eu num conclua o primário esse ano.

(64) Eu não acho que contribua para a violência não, apesar de muitas pessoa0 achare0 que contribua. 
(65) (...) realmente eu acho que seja e muita gente, né?

(66) Eu sou de julgar ninguém não, mas eu.. eu num acho que seja certo.

(67) Ter paixão? Eu num acredito que exista isso (risos) paixão.

(68) Eu acho que a culpa deve ser:: eu acredito mais que seja dos pais.

A única ocorrência de subjuntivo com o verbo crer está associada à presença da negação, como em (69).

(69) Porque eu não creio que numa cidade tão grande como essa ainda tenha gente que fique parada...

A tabela 5 mostra os resultados obtidos em relação à presença/ ausência da negação.

TABELA 5

Resultados do uso do modo subjuntivo nas regiões Nordeste e Sudeste

\begin{tabular}{lllll}
\hline & Sudeste & $\%$ & Nordeste & $\%$ \\
\hline Negação na matriz & $70 / 124$ & $56 \%$ & $50 / 79$ & $63 \%$ \\
Negação na encaixada & $4 / 45$ & $9 \%$ & $18 / 209$ & $8 \%$ \\
Afirmação em ambas & $99 / 396$ & $25 \%$ & $174 / 856$ & $20 \%$ \\
\hline
\end{tabular}

Os resultados relativos aos dados da Paraíba mostram-se em consonância também com as observações de Figueira (1974), para quem a presença da negação não tem consequiências nítidas para o significado. Aproximam-se ainda das observações de Fávero (1974), particularmente no que se refere ao verbo acreditar, o qual, segundo a autora, admite tanto o indicativo quanto o subjuntivo, independentemente da presença da negação.

\subsection{Discussão e análise dos resultados}

O uso quase categórico do subjuntivo com verbos volitivos nos dados da Paraíba vem confirmar a hipótese inicial deste estudo, na qual é postulada maior incidência de formas subjuntivas no português do Nordeste.

Tomando-se por base a classificação das funções dos modos indicativo e subjuntivo proposta em Pereira (1974) e considerando-se o uso quase 
categórico do subjuntivo em construções com verbos volitivos nos dados da Paraíba, podemos afirmar que o uso do modo verbal, nesse contexto, assume valor gramatical, ou seja, o subjuntivo assume a função de marcador da subordinação, exatamente como no PE. Diferentemente, a presença da variação no modo verbal da oração subordinada nos dados do Rio de Janeiro e de Brasília, conforme observado anteriormente (cf. seção 3), indica que o modo verbal não tem valor gramatical na codificação da subordinação (completiva) nessa variedade dialetal. Considerando-se que, nesse caso, a modalidade do enunciado é determinada por propriedades do verbo da matriz, o fato de haver variação quanto à ocorrência da categoria gramatical correlata na oração subordinada indica que as duas variedades dialetais apresentam valores paramétricos distintos em relação à codificação gramatical ou morfossintática da subordinação.

Essa análise se confirma pelo fato de a variável escolarização não ter se mostrado significativa em relação à ocorrência do subjuntivo com verbos volitivos nos dados da Paraíba. Diante disso, exclui-se a possibilidade de considerar que a presença do subjuntivo se deva a processo de ensinoaprendizagem. Inversamente, em relação aos resultados de Rocha (1997), em que se constata o uso variável do subjuntivo e do indicativo com verbos volitivos, é igualmente relevante que a variável escolarização não seja significativa: a ausência da codificação morfofonológica do encaixamento sintático no nível da forma verbal é determinada no nível das operações abstratas que estabelecem os valores paramétricos da gramática em questão, sendo, portanto, definido na gramática internalizada do falante. Nesse sentido, fica demonstrada a relevância de se considerarem variáveis sociolingüísticas na investigação dos fenômenos, cuja manifestação pode propiciar o entendimento mais acurado dos fatos, em particular no que se refere à identificação de propriedades consideradas centrais ou periféricas da gramática.

Quanto ao resultado encontrado com os verbos de opinião, três aspectos se mostram relevantes: (i) o uso variável do subjuntivo e do indicativo é constatado, no francês canadense, no português europeu e nas variedades dialetais do PB examinadas; (ii) existem diferenças entre os diferentes tipos de verbos de opinião no que se refere à manifestação da variação entre o modo subjuntivo e indicativo, em todas as variedades dialetais do PB examinadas; (iii) a negação constitui fator favorecedor do subjuntivo, em todas as variedades dialetais do PB examinadas. 
Em relação ao aspecto observado em (i), o que esse resultado sugere é que os verbos de opinião são compatíveis tanto com a interpretação no complemento de dúvida quanto de certeza no complemento oracional que selecionam. De fato, segundo Figueira (1974, p. 71), "sabendo-se que o subjuntivo é o modo que exprime dúvida, hipótese, compreende-se que o falante sinta a idéia de palpite mais reforçada quando o verbo está no subjuntivo". Como o modo subjuntivo exprime a idéia de dúvida ou hipótese, o falante vai usá-lo como um reforço da idéia de palpite; a manifestação do indicativo na completiva representaria a dispensa do reforço ou redundância, uma vez que a idéia de palpite é indissociável desses verbos. Adotando-se essa abordagem, admite-se que os verbos de opinião são compatíveis com interpretações modais diferentes na oração subordinada, distinguindo-se, portanto, dos verbos volitivos, em que, como mencionado anteriormente, a interpretação modal do enunciado é única / invariável (cf. seção 3 e seção 4.2).

No entanto, outra possibilidade é considerar que o uso da oposição modal não implica a respectiva oposição de interpretação - o que significa atribuir o mesmo valor de verdade aos enunciados e, conseqüentemente, considerar que se trata de variação (laboviana). De fato, muitos falantes, ao serem indagados sobre eventual diferença de significado, diante dos dois tipos de construção, muito freqüentemente não identificam contraste de significado. A conseqüência disso é a neutralização da oposição entre o modo indicativo e subjuntivo no verbo, o que naturalmente não impede que o falante recorra a outros mecanismos gramaticais para codificar lingüisticamente a modalidade do enunciado - é o caso dos recursos lexicais, da utilização de modificadores adverbiais, de recursos prosódicos, conforme ilustrado na seção 2. No entanto, é necessário considerar ainda que o uso que o falante faz das formas lingüísticas nem sempre reflete decisões conscientes, sendo ainda possível pressupor que determinada oposição se encontra realizada em um nível ou domínio da gramática que ainda não foi devidamente identificado ou analisado.

Caberá então aprofundar a investigação para entender as condições que levam à manifestação das formas verbais no indicativo e no subjuntivo com verbos de opinião, a fim de verificar se existe oposição de significado - o que implica atribuir função semântica à oposição morfológica no modo verbal ou se existe neutralização da oposição, não havendo alteração no valor de verdade do enunciado decorrente do uso variável das formas do indicativo e do subjuntivo. 
Em relação ao aspecto observado em (ii), tem-se a constatação de que os diferentes verbos de opinião não têm comportamento idêntico quanto ao uso do modo verbal da subordinada - por exemplo, enquanto 'acreditar' favorece a alternância entre os modos, 'achar' desfavorece a alternância, sendo encontrado preferencialmente com o indicativo. Em relação ao verbo achar, constata-se ainda sua maior freqüência quando comparado aos demais verbos do grupo.

Em estudo de minha autoria (cf. Oliveira, 2005), ressalto o caráter polissêmico do verbo achar e proponho que, particularmente nos contextos associados à semântica da opinião, esteja ocorrendo um processo de gramaticalização, o que, por outro lado, viria explicar a ampla difusão desse verbo. De acordo com Mattos e Silva (2002), traduzindo de Hopper (1998, p.147-154), “a gramaticalização começa quando colocações e formas contextualmente unidas tornam-se habituais e rotineiras, desvinculadas de seus conceitos restritos". Nesse sentido, uma conseqüência do uso rotineiro do verbo 'achar' seria a fixação também da forma verbal na oração complemento, no caso do indicativo, uma situação que poderia ser comparada a uma cristalização - um tipo de fraseologismo no nível morfossintático.

Finalmente, em relação ao aspecto (iii), constatou-se que negação é um fator que, quando presente, especialmente na oração principal, com os verbos de opinião, tende a favorecer o modo subjuntivo na oração completiva. De acordo com Neves (1999, p. 321), esse favorecimento se explica pelo fato de a negação ser uma forma de reduzir o valor de certeza no enunciado, criando ambiente favorável à ocorrência do modo subjuntivo. Fávero (1974) observa que a oração encaixada ligada aos verbos de opinião, chamados por ela de verbos de julgamento, pode ser subjuntivada, mesmo quando a oração matriz não contém negação. Sobre o verbo achar, Fávero (1974, p. 73) afirma: “(...) encontramos com maior freqüência achar com formas verbais do indicativo na oração constituinte; encontramo-lo com formas verbais do subjuntivo na oração constituinte quando vem precedido de negação." (grifo da autora)

Os resultados relativos à negação - em particular a consistência de sua manifestação nos dados examinados no que se refere ao favorecimento do subjuntivo - sugerem que o modo verbal no subjuntivo assume função semântica, pelo menos nesse contexto. No entanto, a relação de implicação constatada nos dados examinados pode ser questionada. Figueira (1974), por exemplo, em relação à presença da negação com os verbos de opinião, não 
vê "conseqüências nítidas para o sentido dos enunciados" (p. 75), como nos dados em (70), (71), (72), (73), em que se verifica a seleção do modo indicativo ou do modo subjuntivo estando a negação na oração matriz ou deslocada para a encaixada.

(70) Eu não acredito que o livro é/ seja caro.

(71) Eu não creio que o livro é/ seja caro.

(72) Eu creio que o livro não é/ seja caro.

(73) Eu acredito que o livro não é/ seja caro.

\section{CONSIDERAÇÕES FINAIS}

O presente estudo examinou o uso do modo verbal em estruturas de complementação no português do Brasil, em confronto com o francês canadense e com o português europeu. Procurou-se investigar a hipótese de que há divergência em relação à seleção do modo verbal em estruturas completivas entre as regiões Nordeste, por um lado, e as regiões Sudeste e Centro-Oeste, por outro.

No desenvolvimento do trabalho, discutimos inicialmente os conceitos de modalidade e modo verbal, por estarem intrinsecamente relacionados, mostrando que o segundo é uma forma de manifestação do primeiro. Para tanto, sistematizamos a contribuição de vários autores, destacando-se o estudo de Pereira (1974), no qual a oposição entre o modo indicativo e subjuntivo no português é caracterizada por meio de três funções: (i) função semântica, em que a alternância entre o modo indicativo e subjuntivo em um mesmo contexto implica oposição semântica; nesse caso, a oração principal não condiciona o modo da oração subordinada; (ii) função gramatical, em que o modo é condicionado pelo verbo da oração principal, sendo específica do subjuntivo, que ocorre como marcador de subordinação; (iii) função semânticogramatical, em que as modalidades expressas pela oração matriz e pela oração encaixada são compatíveis e, ao mesmo tempo, esta é condicionada por aquela, que seleciona um dois modos verbais. A distinção proposta por Pereira mostrou-se adequada à discussão dos nossos resultados. 
Na seqüência, apresentamos o estudo de Rocha (1997), em que são examinadas orações subordinadas substantivas introduzidas pelo complementizador que, tendo como hipótese inicial a perda de campo do modo subjuntivo para o modo indicativo. Os resultados obtidos por Rocha (1997) identificam, por um lado, a entrada do subjuntivo em ambiente previsto para o modo indicativo (verbos indiferentes de opinião) e, por outro lado, a entrada do indicativo em ambiente previsto para o subjuntivo (verbos volitivos). Esses resultados permitem concluir que, nesse contexto, as regiões Sudeste e Centro-Oeste apresentam variação. Ressalta-se também que, ainda que a carga semântica do verbo da matriz seja importante na seleção do verbo da encaixada, conforme atestam as gramáticas tradicionais, outros fatores lingüísticos e extralingüísticos interferem na seleção do modo verbal.

Considerou-se então o estudo de Poplack (1992), também desenvolvido em uma perspectiva variacionista. Essa autora, embora reconheça o papel da semântica do verbo da matriz na seleção do modo verbal da encaixada, questiona o fato de os gramáticos franceses não considerarem outro aspecto a não ser esse e analisa os dados do francês canadense incluindo outros fatores. Em sua análise, contrariando a previsão da gramática tradicional, encontra variação com os verbos volitivos e emotivos e também com os verbos de opinião. Essa variação, entretanto, não permite a afirmação de que o subjuntivo tenha perdido seu sentido nas orações subordinadas substantivas do francês canadense.

Tendo sido demonstrado o uso variável do modo verbal nos estudos citados, passamos à apresentação e análise dos dados do Nordeste (Paraíba), tema do presente estudo. Os resultados obtidos nessa análise confirmaram a hipótese inicial de tendência à retenção do modo subjuntivo: com verbos volitivos, identificamos o uso quase categórico desse modo verbal, (diferentemente do que foi encontrado nas regiões Sudeste e Centro-Oeste e no francês canadense). Esse resultado indicou ainda semelhança com o do português europeu, em que, conforme Mateus et al (2003), o uso do subjuntivo é obrigatório com verbos volitivos. Seguindo a caracterização de Pereira (1974), concluiu-se que o modo verbal nesse caso assume função gramatical, o que significa dizer que ele funciona como um marcador de subordinação. O contraste entre os dados da Paraíba, por um lado, e do Sudeste/Centro Oeste, por outro, permitiram concluir que tais variedades apresentam valores paramétricos diferentes em relação à marcação gramatical das estruturas de subordinação (particularmente com verbos volitivos). 
O fato de a variável escolaridade não ter se mostrado relevante nos dados do Nordeste, onde o subjuntivo se manifesta de forma quase categórica nos ambientes em que seu uso é previsto, tampouco nos dados do Sudeste e Centro-Oeste, que apresentam variação no uso do modo verbal nesse contexto, levou-nos a excluir a possibilidade de que a ocorrência do subjuntivo esteja atrelada ao processo de ensino-aprendizagem. Tal conclusão veio confirmar que a distinção entre as duas gramáticas é determinada no nível paramétrico. Nesse sentido, o uso do modo verbal (subjuntivo) com valor gramatical - isto é, como marcador morfológico do encaixamento sintático é definido no nível da gramática interna do falante, ocorrendo como expressão do um valor paramétrico. A retenção do subjuntivo nos dados da Paraíba indica o caráter conservador dessa gramática em relação ao input na diacronia, que é a gramática do PE. Deduziu-se daí a importância de considerarmos as variáveis sociolingüísticas em nossas análises.

Quanto aos verbos indiferentes de opinião (crer, achar, acreditar), os resultados apontaram para o uso dos dois modos nos dados do Nordeste, mas com amplo uso do modo indicativo. Esse quadro se assemelha ao encontrado nos dados do português do Sudeste/Centro-Oeste, por um lado, e do francês do Canadá, por outro, conforme estudos respectivamente de Rocha (1997) e Poplack (1992) - confirmando-se ainda a descrição (nãovaricionista) de Pereira (1974) e Mateus et al. (2003). Diante disso, sugeriuse que esse grupo de verbos seja compatível com a interpretação de dúvida e de certeza na oração completiva.

Considerando-se os dados da Paraíba, constatou-se variação no uso do modo verbal com o verbo acreditar, como no PE, e também com os verbos crer e achar, o que contraria o que é dito por Mateus et al. em relação ao $\mathrm{PE}$, que favorece o indicativo nesses casos. Em função desse resultado, podese considerar, também, que a ampliação no uso do subjuntivo com esses verbos na matriz corresponde a um caso de variação laboviana, o que representaria uma neutralização da oposição entre os modos.

Outro aspecto discutido nos dados da Paraíba foi a alta freqüência do verbo achar - cuja presença na oração matriz tende a favorecer o modo indicativo, o que se confirma também em Rocha (1997) e Poplack (1992) mesmo apresentando algumas formas do subjuntivo, conforme mencionado. Consideramos então a possibilidade de estabelecer correlação entre a ocorrência quase categórica do indicativo e o fato de que esse verbo, em 
ambiente de opinião, esteja passando por um processo de gramaticalização, conforme proposto em Oliveira (2005). Nesse sentido, cabe uma investigação mais aprofundada das condições que levam à manifestação variável dos modos verbais com os verbos de opinião.

Finalmente, discutiu-se o papel da negação. Conforme demonstrado nos estudos prévios, com verbos (indiferentes) de opinião, a negação favorece o modo subjuntivo na oração encaixada. Esse favorecimento se confirmou também nos dados da Paraíba (embora o subjuntivo tenha se manifestado em orações afirmativas com os verbos acreditar e achar). De acordo com vários estudos, esse resultado é decorrência da compatibilidade semântica entre a negação e o subjuntivo, embora não haja condicionamento mútuo, como mencionado por Figueira (1974) e Fávero (1974).

Os resultados obtidos com a presente discussão sugerem a relevância de se investigar que fatores estão associados à manifestação conservadora da gramática nos dados da Paraíba, em oposição ao caráter inovador da gramática nos dados do Sudeste/ Centro-Oeste, entre outras questões que contamos examinar em pesquisa futura.

\section{NOTAS}

${ }^{1}$ Este trabalho foi desenvolvido no âmbito da Pós-Graduação em Lingüística da Universidade de Brasília, sob a orientação da Profa. Heloísa Salles e da Profa. Marta Scherre, a quem gostaria de agradecer pelas discussões e pelo apoio recebido.

${ }^{2}$ Ignora-se aqui o fato de que orações substantivas na função de sujeito têm sido analisadas como completivas na função de objeto direto.

${ }^{3}$ Agradeço à Profa. Marta Scherre por sugerir a inclusão da abordagem sobre o modo imperativo.

${ }^{4}$ Os exemplos de (20) a (24) apontados a seguir, são fruto de inferência feita a partir de estudo dos dados analisados no trabalho de Pereira (1974), visto que a autora não forneceu exemplos específicos para cada função.

${ }^{5}$ Predicado factivo é aquele cujo sujeito ou complemento oracional é pressuposto pelo locutor como expressando uma proposição verdadeira, i.é, a oração que funciona como sujeito ou complemento de um verbo factivo é uma pressuposição para a oração como um todo. (PEREIRA, 1974, p. 88) 
${ }^{6}$ Também são denominados verbos de atividade mental ou epistêmicos (MATEUS et al. 2003, p. 261); de julgamento (FILLMORE, 1971 in LAFUENTES, 1982). São verbos de atividade mental, segundo Moura Neves (1999, p. 347) aceitar, achar, acreditar, admitir, calcular, compreender, considerar, certificar, crer, descobrir, duvidar, entender, fingir, ignorar, imaginar, pensar, prever, predizer, reconhecer, supor.

${ }^{7}$ Conforme definição obtida em Rocha (1997, p. 50), predicados indiferentes são formados por um tipo de verbo que sintaticamente tem características dos predicados factivos e dos não factivos, isto é, aceita os dois modos verbais na oração encaixada, sendo que a leitura factiva ou não factiva depende de outras características sintáticas. Desse grupo, alguns só são indiferentes quando negados e outros, os que nos interessam para este estudo, caracterizam-se por não atribuir à oração subordinada um valor de verdade que possa ser inferido. Esses verbos expressam suposições, opiniões subjetivas, expressões de recordação.

${ }^{8} \mathrm{O}$ verbo pedir faz parte, de acordo com a classificação utilizada por Pereira (1974, p. 88, 197), da categoria semântica dos não-factivos e não-volitivos. Esse grupo verbal é caracterizado como o que apresenta uma atitude neutra do locutor: não afirma nem nega que a pressuposição da oração encaixada seja verdadeira.

${ }^{9} \mathrm{O}$ estudo de Farias (2005), que tem enfoque parcialmente quantitativo, além de identificar a variação entre o subjuntivo e o indicativo nas orações concessivas (mas não na adversativa, que, como é de se esperar, apresenta o uso categórico do indicativo), estabelece correlação entre essa variação e a reanálise da conjunção 'mas' como introdutora da oração concessiva, um fato que se sobressai nos dados e que remete à discussão sobre a gramaticalização de marcadores discursivos como categorias sintáticas.

${ }^{10}$ Em Mateus et al. (2003, p. 277), o verbo pedir é classificado com verbo de inquirição; Poplack (1992) classifica-o como volitivo, classificação adotada no presente estudo; Lafuentes (1982, p. 72) classifica-o com verbo de solicitação e Fávero (1974, p. 60) classifica-o como verbo que expressa atitude volitivo-imperativa.

${ }^{11}$ Além da oração completiva finita, verificamos que o verbo pedir também apresenta ocorrências de complementação com o infinitivo, mantendo-se o mesmo conteúdo proposicional.

(i) (...) e peço a Deus todo dia pra acertar.

(ii) Ele pediu pra eu acompanhar ele.

(iii) Mariana chegou cum padre Livio pidindo pra Zé Inocêncio aceitar ela de vouta... 
Interessante notar que, nesses contextos, as propriedades semânticas do verbo da matriz mostram-se compatíveis com as da preposição para: no caso do verbo, é a orientação para uma volição, um desejo; no caso da preposição, é a orientação para uma meta.

\section{REFERÊNCIAS BIBLIOGRÁFICAS}

BECHARA, Evanildo. Moderna Gramática Portuguesa. 37. ed. Rio de Janeiro: Lucerna, 1999.

CARDOSO, Daisy Bárbara Borges. Variação no uso do modo imperativo: análise de dados em textos de José J. Veiga. 2004. Dissertação (Mestrado em Linguiística) - Universidade de Brasília, Brasília.

CHOMSKY, Noam. Lectures on Government and Binding. Dordrecht: Foris, 1981.

Praeger, 1986.

Knowledge of Language: Its Nature, Origin and Use. New York:

CUNHA, Celso; CINTRA, Luís F. Lindley. Nova gramática do português contemporâneo. 2. ed. Rio de Janeiro: Nova Fronteira, 1985.

DA HORA, Dermeval; PEDROSA, Juliene L. Ribeiro. Projeto Variação Lingüística no Estado da Paraíba. João Pessoa: Idéia, 2001.

DUBOIS et al. Dicionário de Lingüística. 9. ed. São Paulo: Cultrix, 2004.

DUCROT, O; TODOROV, T. Dicionário das Ciências da Linguagem. Lisboa: Publicação Dom Quixote, 1977.

FARIAS, Rosemeire Lopes da Silva. A oposição indicativo/ subjuntivo e o uso das conjunções 'mas' e 'embora' em textos de alunos da educação básica. 135f. 2005. Dissertação (Mestrado) - UnB.

FÁVERO, Leonor Lopes. Complementação de Predicado em Português. 1974. Dissertação (Doutorado) - PUC/ SP.

FIGUEIRA, Rosa Attié. Verbos introdutores de pressupostos. 1974. Dissertação (Mestrado) - UNICAMP.

LABOV, W. Sociolinguistcs Patterns. Philadelphia: University of Pennsylvnia Press, 1972. 
LABOV, W. Language Variation and Change. Cambridge University Press, 1990. LAFUENTES, Dayse Paiva Castro. Verbos de julgamento. 1982. Dissertação (Mestrado) - Universidade de Mogi das Cruzes.

LIMA, Damaris Pereira Santana. Uso do imperativo gramatical na fala de Campo Grande (MS). Dissertação de mestrado, 2005.

MATEUS et al. Gramática da Língua Portuguesa. 2. ed. Lisboa: Caminho, 1989. MATTOS E SILVA, Rosa Virgínia. "A gramaticalização numa perspectiva diacrônica: contribuições baianas." Encontro da ANPOLL/ 2002. Disponível em: <htpp//www.prohpor.ufba.br/gramaticaliza.html>.

MATTOSO CÂMARA, Jr. J. Dicionário de Lingüística e Gramática. 9. ed. Rio de Janeiro: Vozes, 1981.

NEVES, Maria Helena Moura. Gramática de usos de português. 4. ed. São Paulo: Unesp, 1999.

OLIVEIRAE SILVA, Giselle Machline; PAIVA, Maria da Conceição Auxiliadora de. Visão de conjunto das variáveis sociais. In: OLIVEIRA E SILVA, Giselle Machline; SCHERRE, Maria Marta Pereira (Org.). Padrões sociolingüísticos: análises de fenômenos variáveis do português falado na cidade do Rio de Janeiro. Rio de Janeiro: Tempo brasileiro, 1996. p. 335-378.

OLIVEIRA, Maria do Carmo. O verbo achar nos dados da Paraíba e nos Diálogos de São Gregório. [Universidade de Brasília, ms.], 2005.

PEREIRA, Maria Ângela Botelho. Aspectos da oposição modal indicativo/ subjuntivo no português contemporâneo. 256f. 1974. Dissertação (Mestrado) UFRJ, Rio de Janeiro.

POPLACK, Shana. The inherent variability of the French subjunctive. In: Theorical analyses in romance linguistics. Amsterdam: John Benhamins publishing company, 1992. p.235-263.

ROCHA, Rosa Cecília Freire da. A alternância indicativo/ subjuntivo nas orações subordinadas substantivas em português. 123f. 1997. Dissertação (Mestrado) - UnB, Brasília.

SAID ALI, M. Gramática secundária e gramática histórica da língua portuguesa. Brasília: Editora da UnB, 1964. 
SAMPAIO, Dilcélia Almeida. Modo imperativo: sua manifestação/expressão no português contemporâneo. 2001. Dissertação (Mestrado) - UFBA, Salvador. Inédito.

SCHERRE, Maria Marta Pereira. A norma do imperativo e o imperativo da norma - Uma reflexão sociolingüística sobre o conceito de erro. In: BAGNO, Marcos (Org.). Lingüística da Norma. São Paulo: Loyola, 2002. p. 217-265.

TEIXEIRA DE JESUS, Étel. Uso do imperativo na novela Senhora do destino: estereótipo ou identidade. Trabalho apresentado na SBPC/ julho de 2005. Fortaleza. 